\title{
LAS HORAS: ESTUDIO COMPARATIVO ENTRE LA SENORA DALLOWAY DE VIRGINIA WOOLF, LAS HORAS DE MICHAEL CUNNINGHAM Y LAS HORAS DE STEPHEN DALDRY
}

\author{
Sandra Medina Rodríguez \\ UMCE
}

\section{RESUMEN}

En 2002 Stephen Daldry estrenaba el film Las horas, inspirado en el libro homónimo publicado en 1998 por Michael Cunningham. Cunningham, a su vez, había escrito su obra para homenajear a la autora inglesa Virginia Woolf y, más concretamente, su novela La señora Dalloway. En el presente estudio, como principal objetivo, analizaremos los artificios y engranajes que operan en la intertextualidad de las tres obras. Identificaremos las estrategias narrativas empleadas en cada una de ellas y evidenciaremos tanto las diferencias como las semejanzas entre las tres. Profundizaremos en los dispositivos de los que se sirve el cine para trasladar a la gran pantalla los textos narrativos tanto de Woolf como de Cunningham.

Palabras clave: Virginia Woolf, Michael Cunningham, Stephen Daldry, La señora Dalloway, Las horas, literatura comparada.

\author{
VIRGINIA WOOLF'S MRS. DALLOWAY, MICHAEL CUNNINGHAM'S \\ THE HOURS AND STEPHEN DALDRY'S THE HOURS: A COMPARATIVE STUDY
}

\section{Abstract}

In 2002 Stephen Daldry premiered the film The hours, inspired by the homonymous book published in 1998 by Michael Cunningham. Cunningham, in turn, had written his work to honor the english author Virginia Woolf and, more specifically, his novel Mrs. Dalloway. In the present study, as the main objective, we will analyze the artifices and gears that operate in the intertextuality of the three works. We will identify the narrative strategies used in each of them and we will demonstrate both the differences and the similarities between the three. We will deepen into the devices that the cinema uses to transfer the narrative texts of both Woolf and Cunningham to the big screen.

Keywords: Virginia Woolf, Michael Cunningham, Stephen Daldry, Mrs. Dalloway, The Hours, comparative literatura. 


\section{INTRODUCCIÓN}

[El cine] ¿Cuáles son esos recursos que tiene? [...]. ¿Hay alguna característica que posea el pensamiento y que pueda plasmarse visiblemente sin ayuda de las palabras? Tiene velocidad y tiene lentitud, tiene las virtudes de una flecha, a la par que una circunlocución vaporosa. Pero también tiene, especialmente en los momentos de emoción, el poder de plasmarse en imágenes, la necesidad de cargar su pesado fardo sobre estos hombros. Por algún motivo, la semejanza del pensamiento es más bella, más comprensible, más asequible, que el pensamiento mismo.

Virginia Woolf, (2016: 326-327)

El cine visto por los escépticos ojos de Virginia Woolf, quien asistió a su nacimiento y primeros pasos, no era solamente un ave rapaz que se apropiaba de la literatura, entre otras artes, engullendo indiscriminadamente cualquier novela. Además de esta acusación, si seguimos leyendo sus apreciaciones sobre el séptimo arte, a Woolf esta plasmación de imágenes le parecía superficial: «... En Shakespeare las ideas más complejas forman cadenas de imágenes [...]. Son un compendio de millares sugerencias, de la cual la visual es solo la más obvia, o la superior» (Woolf, 2016: 327-328).

Si bien la autora británica tenía sus reservas hacia el cine, también vislumbró sus posibilidades futuras. Unas posibilidades que, como escritora de un nuevo lenguaje en el que el tiempo trataba de ser abolido en una narrativa de imágenes simbólicas, puede que incluso envidiara, como podríamos interpretar en las siguientes sentencias (Woolf, 2016):

Los contrastes más fantásticos podrían centellear ante nuestros ojos con una velocidad tras la cual el escritor sólo podrá desvivirse en vano. [...] El pasado podría desplegarse ante nuestros ojos, aniquilarse las distancias y esos abismos que dislocan las novelas [...] bien podrían gracias a la igualdad del telón de fondo, a la repetición de una escena, pasar inadvertidos (329).

El cine irrumpió coincidiendo con un momento de ruptura en la narrativa occidental con la novela decimonónica, y muchas de sus estrategias narrativas fueron inspiración para escritores como James Joyce. Las teorías del montaje de Sergei Eisenstein y el cine de David Wark Griffth (El nacimiento de una nación, 1915, e Intolerancia, 1916) revolucionaron las formas del relato y el tratamiento del tiempo en el cine. Se fundían las imágenes, cargadas de simbolismo, en un arte que podía llegar a manejar el tiempo a su antojo, sin brusquedad ni torpeza. Algo a lo que aspiraba la narrativa woolfiana: un encadenamiento de imágenes poéticas y simbólicas, en las que el pasado y el presente se fusionaran en una atemporalidad. Una ambición que, precisamente tres cuartos de siglo después de su obra emblemática, La señora Dalloway (1925), se consiguió plasmar en la versión cinematográfica de esta, Las horas (2002) de Stephen Daldry. Esta última está basada, a su vez, en el homenaje que el escritor Michael Cunningham rindiera en 1998 a Virginia Woolf en su novela también titulada Las horas. 


\section{TODO LO SÓLIDO SE DESVANECE EN EL AIRE. EL MODERNISMO LITERARIO INGLÉS ${ }^{1}$}

Todas las relaciones humanas se han modificado; las relaciones entre señores y criados, entre maridos y mujeres, entre padres e hijos. Y cuando cambian las relaciones humanas, se produce al mismo tiempo un cambio en la religión, en la conducta, en la política y en la literatura.

Virginia Woolf (citada por Marder, 1979: 39)

La propia definición de modernismo anglosajón está sujeta a debate y controversia. Generalmente se entiende como modernismo inglés la producción literaria desarrollada entre la década de los años veinte y treinta del s. xx. Como año decisivo para el modernismo se señala constantemente 1922: James Joyce, George Eliot y Virginia Woolf publican Ulises, La tierra baldia y El cuarto de Jacob respectivamente. Junto con otras obras cercanas en el tiempo, hay similitudes que justifican emplear la misma etiqueta que ampare la producción literaria de ese periodo. Sin embargo, también hay una disparidad considerable entre autores tan distintos entre sí como fueron James Joyce, D.H. Lawrence o George Bernard Shaw. En todo caso, nos acogemos al marco propuesto por Alberto Lázaro (2005: 35), en el que establece tres fases del movimiento: una inicial, con autores como Henry James y Joseph Conrad en torno a finales del s. XIX y principios del s. XX, una segunda etapa de madurez, en las décadas de los años veinte y treinta, en la que destacan Woolf y Joyce, y una última fase final, con epígonos de este movimiento, en los que sobresalen Beckett y Lawrence Durrell.

Las décadas finales del s. XIX estuvieron marcadas por la inestabilidad política y social resultado de las ambiciones imperialistas europeas, de la creciente violencia de las revueltas en Irlanda, de las desigualdades de clases generadas por la segunda revolución industrial en Inglaterra y el estallido de conflictos como la I Guerra Mundial y la Revolución Rusa. Movimientos como el sufragismo femenino y la Sociedad Fabiana sacudían ${ }^{2}$ los cimientos del estricto y clasista orden establecido por la Inglaterra decimonónica, aferrada aún al positivismo y al racionalismo. Jóvenes británicos, como Woolf, contemplaban con escepticismo la herencia victoriana con una mirada pesimista a un presente y futuro muy inciertos, evidenciando una fractura generacional abismal e insoluble. Los valores de sus padres, como la familia y el deber patriótico, se resquebrajaban. Así lo describía la propia escritora en Moments of Being (1985):

1 Tomamos prestado aquí el título del excelente ensayo sobre la modernidad escrito por el filósofo Marshall Berman (1940-2013), publicado en 1982. Berman, a su vez, había extraído la frase del Manifiesto comunista de Karl Marx.

2 La Sociedad Fabiana, fundada en 1884, era una asociación política que promovía la instauración de los principios socialistas de forma paulatina, sin revueltas violentas. Fue el germen del partido laboralista y a ella pertenecieron George Bernard Shaw, Emmeline Pankhurst o H.G. Wells. 
Dos edades diferentes se enfrentaban en el cuarto de estar [...]. La edad victoriana y la eduardiana [...]. Pero mientras nosotros mirábamos hacia el futuro, estábamos bajo el control absoluto del pasado [...]. Por lo tanto teníamos dos batallas en las que luchar [...] una como seres individuales; y otra contra ellos en como seres sociales. Nosotros vivíamos, por ejemplo, en 1910; ellos vivían en 1860 (147).

El crecimiento exponencial de las ciudades, que albergaban la mano de obra rural atraída por la industria junto con una revolución tecnológica (los coches, la mecanización, el cine, el avión, la electricidad...) generó unas metrópolis repletas de nuevos ruidos y en las que todo se movía a una gran velocidad, escenario común de la mayoría de los escritores modernistas. Londres, París, Berlín y demás capitales europeas se transformaban a una velocidad vertiginosa y las desigualdades generaban conflictos sociales cada vez más cruentos.

Las teorías filosóficas que cuestionaron conceptos y valores hasta esos momentos absolutos cambiaron la percepción del mundo, desde descubrimientos como el de la existencia de los átomos hasta las nuevas teorías sobre la luz. El tiempo se planteaba ahora como un término relativo, como Albert Einstein (18791955) lo describía en 1905. Martin Heidegger (1889-1976) defendía que, sin consciencia, no hay tiempo y que solo existe en cuanto hay una consciencia capaz de percibirlo. A su vez, Henri Bergson (1859-1914) postulaba sobre la posibilidad de que el tiempo fuera algo intuitivo, interno, coexistiendo con el tiempo exterior, el que marca las agujas de un reloj. Este tiempo subjetivo, intuido, se escapa al raciocinio. Es un tiempo en el que la consciencia, a través de la memoria, es atemporal, haciendo que el pasado sea perceptible en el presente.

El auge de la antropología, de los estudios clásicos e historia antigua y de las formas primitivas puso en valor la mitología, tanto centroeuropea como grecolatina, influyendo en la literatura modernista, en obras como Ulises. Friedrich Nietzsche (1844-1900) retomaría de la Antigüedad conceptos como el eterno retorno y enfrentaría nociones como lo apolíneo y lo dionisíaco, la mesura y la razón frente a la imaginación y lo irracional, abogando por estas últimas. Pero, sin lugar a duda, fue la psicología la fuente de inspiración que impregnó la literatura modernista. Sigmund Freud (1856-1939) publicó en 1899 La interpretación de los sueños y desarrolló las célebres teorías del funcionamiento de la mente humana, centrándose en los mecanismos y procesos del subconsciente. Su repercusión fue de una magnitud inmensurable. Debemos destacar también la importancia de la obra del psicólogo William James (1842-1910), hermano de Henry James. James concebía en The Principles of Psychology (1890) la conciencia como una corriente, un flujo de imágenes, impresiones y palabras que manaba y fluía de forma irracional, inarticulada, denominándola stream of consciousness ${ }^{3}$. Este concepto repercutió en la narrativa modernista, sobre todo en las novelas de Virginia Woolf.

\footnotetext{
${ }^{3}$ Debemos aclarar la diferencia con el monólogo interior, acogiéndonos a la distinción de Bowling, según la cual «el flujo de consciencia sería una subclase del monólogo interior: la comuni-
} 
Se manifestaba desconfianza en un lenguaje incapaz de comunicar de forma inequívoca, de transmitir ideas de forma universal: «Nada debería tener nombre por temor a que al nombrar cambiemos las cosas", escribía en 1931 Virginia Woolf en Las olas (201). Ludwig Wittgenstein (1889-1951) y Bertrand Russell (1872-1970), este último parte del grupo de Bloomsbury, exploraban la relación entre el mundo y su representación, por medio de la palabra. Para ellos, pensamiento, imágenes y palabras son producto de una asociación de imágenes y/o lingüística en lugar de ser el resultado de un proceso analítico y deductivo. Esta asociación será pues arbitraria, individual y cuestionable.

\section{LA NARRATIVA MODERNISTA}

La narrativa del s. XIX se esforzaba por representar el mundo tal y como era, desde un punto de vista de un narrador extradiegético, objetivo y omnisciente, que nos narraba la realidad de manera íntegra e imparcial. Las descripciones de una sociedad injusta a modo de denuncia social, como eran las narraciones de Charles Dickens (1812-1870) o Victor Hugo (1802-1885), recreaban un mundo casuístico con continuos efectos causa-consecuencia, ordenados en una temporalidad lineal. La finalidad era en muchos casos didáctica y moralizante: se desprendía que de las observaciones objetivas expuestas relucían verdades universales e inequívocas que los lectores debían aprehender para ser mejores ciudadanos. Los escritores modernistas percibían un agotamiento del realismo, anclado en un viejo mundo que se desmoronaba y cuyos valores ya no eran válidos. Precisaban de un nuevo lenguaje adecuado a la nueva era que ya había llegado. Susan Sontag (citada en López-Varela, 2002) lo analiza así:

La experimentación formal tan central del Modernismo se puede interpretar como una tentativa para escapar de las limitaciones del lenguaje, que se contempla como producto de una disyunción entre el ser y el mundo y se experimenta como corrupto, caído, pesado bajo la acumulación histórica (117).

Se inició así una ruptura con las estrategias narrativas, las temáticas y los fines con la tradición realista inglesa, en la que la experimentación formal fue constante y profunda. La búsqueda de un nuevo lenguaje centró gran parte de sus discursos en el propio proceso creativo y el oficio literario. Las temáticas reflejaban la vida interior, las emociones y pensamientos de los personajes, autodefinidos por medio de monólogos interiores, directos o indirectos, que transmitían imágenes sugerentes, poéticas y subjetivas. El individuo era el centro del universo narrativo y las novelas profundizaban en los mecanismos de percepción que lo alejaban y aislaban del mundo exterior. La soledad y la imposibilidad de comunicación eran dos

cación, por medio de una transformación verbal convencional, de las impresiones de los sentidos no articuladas de un personaje, ordenadas aleatoriamente» (citado por Chatman, 1990: 202). 
de los temas recurrentes. Personajes aislados y ajenos a la sociedad, que reflexionaban sobre el paso del tiempo, imbuidos en abrumadoras y tecnificadas ciudades. La lupa de los modernistas se dirigió a lo cotidiano. El día y las horas. Lo trágico en lo "común", en un paseo por las calles de Dublín o en la preparación de una fiesta. Los novelistas se centraron en retratar o interpretar lo rutinario y su percepción en la mente humana. Genette (1989: 153) pone de relieve la intención modernista de mostrar más que narrar, de minimizar la mimesis en favor de la diégesis. La tendencia hasta entonces de la narrativa, que alternaba sumario y escena, se desvanece en la nueva narrativa, en la que el sumario fue perdiendo presencia.

La linealidad temporal fue abandonada en favor de una temporalidad fragmentada, dispersa, como lo percibe nuestra mente. En el flujo de imágenes y palabras que es la consciencia el tiempo no es lineal; la memoria se funde con el pensamiento en el presente sin distinciones temporales. Encontramos así un pasado-presente continuo que nos infunde una sensación constante de simultaneidad. La modernidad experimentó la relación entre tiempo narrativo y el tiempo de la historia mediante el empleo de verbos en presente, resquebrajando el orden clásico de la literatura decimonónica. La prosa intentó asemejarse a la poesía, deteniéndose en la contemplación poética del instante de un héroe pasivo, que desplaza el interés de los acontecimientos y causalidades.

Se diluyó la presencia del narrador en un intento de percibir sin intermediarios la consciencia de los personajes, sus pensamientos (Gutiérrez, 2000: 1). Estos pensamientos se manifestaban en imágenes verbales fragmentarias. Por otro lado, el narrador en el modernismo es cambiante: hay multiplicidad de narradores que recrean en la literatura el flujo constante y mudable de la vida moderna en las ciudades. Estos múltiples puntos de vista configuran el mundo bajo el tamiz de sus percepciones. Siguiendo el esquema de Genette, la frecuencia repetitiva es propia y usual en la literatura modernista, al mostrar los hechos, los mismos sucesos, desde distintas consciencias (Genette, 1989: 174).

\section{VIRGINIA WOOLF Y LA SEÑORA DALLOWAY}

La vida, quizás, no se presta a las manipulaciones a las que la sometemos cuando intentamos contarla.

Virginia Woolf (2003b: 347)

Dentro del modernismo anglosajón Virginia Woolf es una figura clave. $\mathrm{La}$ señora Dalloway, como hemos ya indicado, es considerada la obra insigne de la madurez experimental de Virginia Woolf. Virginia tenía cuarenta años cuando comenzó a escribir la vida, que en un principio iba a titularse Las horas, de una mujer en un solo día. El proceso creativo, como se refleja en Las horas, novela y película, fue tortuoso: Virginia se recuperaba en Richmond, entre el tedio y la desesperación, de una crisis nerviosa. No es de extrañar que Virginia Woolf quisiera que su novela fuera «un estudio de la locura y el suicidio; el mundo visto por el sano y el insano 
de lado a lado" atacando a su vez al sistema social y político que le tocó en suerte vivir (Woolf, 1981: 248)

Clarissa Dalloway es una mujer de mediana edad, casada con un político laborista, Richard Dalloway, que se dispone a dar una fiesta. Su vida es anodina e insatisfactoria, pero gracias a rellenar las horas con trivialidades sobrevive. Los recuerdos de un pasado en el que aún podía ser libre y feliz le sobrevienen, como breves epifanías, a través de la percepción de objetos o situaciones: el frío de una mañana asomada a la ventana la devuelve al frescor de la mañana en que tenía dieciocho años, el reencuentro con su antiguo amor Peter Walsh la retrotrae a la mujer que era antes de ser la señora Dalloway.

Septimus Warren Smith, a quien nunca conocerá Clarissa, es un veterano de la Primera Guerra Mundial que vive atormentado ante la imposibilidad de encontrar un nuevo lenguaje con el que expresar el horror vivido en las trincheras. Al contrario que Clarissa, es incapaz de aferrarse a las horas y dejar de vivir las atrocidades de la batalla que evoca constantemente en su mente. Con este breve resumen dejamos entrever las cuestiones planteadas por Woolf, a saber: el paso del tiempo, la incapacidad del lenguaje que aísla e incomunica, la locura, la memoria, el suicidio como escapatoria, lo cotidiano como salvación.

La señora Dalloway relata un día en la vida de Clarissa, pero la historia abarca treinta y tres años: desde el verano de Bourton en 1890 hasta el verano de 1923. La novela se concentra en estas dos fechas y relata con breves pinceladas momentos vividos entre ambas. Las escenas se suceden divididas por elipsis y requieren la complicidad del lector para construir esos vacíos, siendo una narrativa más cinematográfica (Chatman, 1990: 79). La narración, que comienza con los pensamientos de Clarissa, va fluyendo por múltiples narradores de forma fragmentaria en monólogos interiores en estilo indirecto: es una narración omnisciente multiselectiva. Woolf difuminó su propia voz hasta desaparecer, y con ella se esfumaba el intermediario entre las mentes de los personajes y nosotros, los lectores. Woolf parece estar ausente en su propia novela, pero sin embargo la percibimos diseminada en diversos personajes: está en Septimus y su «locura», en la señora Dalloway y sus horas llenas de insatisfacción. Los cambios de narrador transcurren de una forma fluida, en la misma frase, en la que podemos encontrar pinceladas, pensamientos sueltos, de varios personajes, como podemos apreciar en el siguiente fragmento (Woolf, 2003a: 150): «[Clarissa] se irguió un poco sobre el bordillo, esperando que pasara un camión, el camión de Durtnall. Una mujer encantadora, pensó Scrope Purvis (que la conocía como uno conoce a los vecinos de Westminster)».

La ambigüedad en los monólogos de La señora Dalloway funde la voz de Virginia con la de sus personajes, uniendo así las dos voces, una técnica narrativa que Chatman (1990: 222) define como estilo indirecto libre «neutralizado».

${ }^{4}$ Traducción de «I want to give and death, sanity and insanity, i want to criticise the social system». 
Son frecuentes en su narrativa las imágenes reiterativas, leitmotivs, que dan cohesión y dotan de simbolismo al relato. Pero esta carga alegórica no tiene un significado unívoco en la bibliografía de Woolf, ni siquiera en la misma obra. De la misma manera, los hechos del mundo exterior, además de crear cohesión, refuerzan y configuran la sensación de simultaneidad: los diversos personajes, que ni siquiera se conocen, que miran expectantes las letras esbozadas en el cielo por una avioneta sacando conclusiones distintas y propias en La señora Dalloway. Son hilos woolfianos que unen de forma casi casual y aleatoria a sus personajes en un mismo momento, recuerdo o pensamiento, en delicados hilos casi imperceptibles en la vorágine de la vida moderna. Londres proporciona los espacios donde, mediando el azar, se entrelazan los hilos que unen a los personajes haciendo que fluya la narración, como si el tejido urbano (el mundo exterior) dejara entrever ocasionalmente las consciencias de sus personajes (Lozano, 2003: 129). En La señora Dalloway, en la gran urbe que es la capital inglesa, las periódicas campanadas del Big Ben retornan a sus personajes desde su tiempo interior al exterior, interrumpiendo su suspensión en su propio tiempo para devolverlos al tiempo del «mundo real». Es la llamada al orden de una civilización que trata de organizar el tiempo de una forma artificial.

Virginia crea contrastes entre imágenes o metáforas que describen objetos o acciones contrapuestas como, por ejemplo, el subir de las escaleras de La señora Dalloway durante su fiesta con, simultáneamente, la caída desde la ventana de Septimus. La coronación de Clarissa como perfecta anfitriona de la celebración de la vida y el descenso de Septimus hacia la muerte. Esta escena es una reminiscencia del inicio de la novela, pues, como indica María Lozano (2003: 136), ya en la primera página Woolf nos la anticipa en esta frase, que se pierde en algunas traducciones al castellano: What a lark! What a plunge (¡Vaya deleite!, en el sentido de subida emocional, y ¡Vaya zambullida!, con connotaciones de caída).

El pasado se hace presente mediante la combinación de tiempos verbales y la elección de adverbios. En este sentido, Woolf recurre a mecanismos narrativos como las diferentes conjugaciones verbales en un mismo párrafo: el uso del infinito y el pasado en una misma frase, o el empleo de conectores que sugieran una fluida continuidad entre pasado y presente, como el for. Así también, para reforzar la idea de la inexistencia de verdades absolutas y del individualismo, el continuado uso de if o del verbo seem (Lozano, 2003: 135). Veamos un ejemplo clarificador de lo que tratamos de explicar: «Porque de tanto vivir en Westminster ¡cuántos años ya? más de veinte- sientes, aún en medio del tráfico o al despertarte de noche, Clarissa estaba segurísima, una inquietud particular» (Woolf, 2003a: 150).

Woolf emplea figuras literarias en las que, pese a que los pensamientos son fragmentarios, se consigue unión y fluidez narrativa. Así encontramos en La señora Dalloway la epizeuxis: la repetición de palabras en un mismo verso, la anáfora: una palabra o conjunto de palabras se emplea en el inicio de frases correlativas, la anadiplosis: la palabra final de una oración coincide con el principio de la siguiente. Las páginas de la novela están repletas de ejemplos como los que proponemos a continuación (Woolf, 2003a: 162, 165 y 169): 
Septimus Warren Smith, incapaz de cruzar, lo oyó.

Septimus Warren Smith, unos treinta años (...).

Clarissa lo adivinada, Clarissa lo sabía.

Lucrezia Warren Smith (...) levantó la mirada.

-¡Mira, mira, Septimus!

La manipulación de la sintaxis de Woolf es evidente en La señora Dalloway, desplazando el verbo al final de la oración, separándolo del sujeto: crea así un impulso, suspense en cada frase. Virginia ejerce una libertad con la que desordena las oraciones aumentando la sensación de confusión.

En La señora Dalloway hay elementos que se repiten: las flores, con las que se inicia la novela, las flores que le lleva Rezia a su trastornado esposo Septimus, las que le regala Richard a Clarissa al llegar a casa, las flores como celebración de la vida y como medio de expresar el amor que es incapaz de verbalizar su esposo. Las flores como detonante de los recuerdos más añorados de su vida.

También las olas, las ondas expansivas de un río y del mar. El agua como símbolo del paso del tiempo, de la vida y la muerte, está presente, como advertimos, en frases como «como la planta del lecho del río se estremece al sentir la onda de un remo: tal fue su temblor, tal fue su estremecimiento» o en "como el golpe de una ola; como el beso de una ola; fresco y penetrante» (Woolf, 2003a: 177 y 149).

La ventana como elemento simbólico es muy recurrente en la narrativa woolfiana. En La señora Dalloway encontramos la ventana desde la que se lanza Septimus, la ventana desde la que, al principio de la novela, Clarissa observa el bullicio de la vida, y desde la que al final descubre a la anciana, solitaria y envejecida, como una anticipación del fin de sus horas.

La cama, que, como señala Lozano (2003: 278), se reitera en varias páginas, funciona como una metáfora del aislamiento: la propia Virginia se vio postrada en ella a causa de su enfermedad y para Clarissa Dalloway la cama es escenario de sus frustraciones sexuales. El mismo nombre de Clarissa ya tiene connotaciones religiosas, pues ella se siente como una virgen casta, una monja pura e inmaculada, recordándonos los problemas sexuales de la propia Woolf.

\section{MICHAEL CUNNINGHAM Y LA SEÑORA DALLOWAY}

Las fronteras de un libro nunca son claras: más allá del título, las primeras líneas y la última parada completa, más allá de su configuración interna y su forma autónoma, se encuentra atrapado en un sistema de referencias a otros libros, otros textos, otras oraciones: es un nodo dentro de una red [...]. El libro no es simplemente el objeto que uno tiene en las manos.

Michel Foucault (1970: 37)

La huella dejada por Virginia Woolf en la literatura ha sido ampliamente reconocida y hoy en día se la considera un icono literario y feminista. Su influencia 
en escritores eternos como Julio Cortázar y Jorge Luis Borges (quienes tradujeron al castellano sus obras) es incuestionable. Michael Cunningham (1955, Cincinnati), profesor de escritura de la Universidad de Columbia, quiso homenajear a la autora inglesa publicando en 1998 una novela, Las horas, que cosechó, al año siguiente, los premios PEN/Faulkner y el Pulitzer. Las horas, título que la propia Virginia Woolf pensó ponerle a La señora Dalloway, es un entramado de juego intertextual entre Cunningham, la novela de la escritora y la propia vida personal Virginia Woolf.

Cunningham, como Woolf, concentró la narración en un día, pero en este caso, de tres mujeres. Una es la propia Virginia el día que inicia la escritura de $L a$ señora Dalloway, una mañana de verano de 1923, otra es Laura Brown, una ama de casa de Los Ángeles que, en 1949, lee esa misma novela, y la tercera es la personificación de Clarissa Dalloway, Clarissa Vaughan, el año en que Cunningham escribió Las horas, 1998. Tenemos, pues, que Las horas se valió de los protagonistas de La señora Dalloway como patrones, sin continuar sus vidas originales, para la creación de personajes que tienen una vida distinta, pero en algún sentido paralela. Es lo que Chatman (citado por Cánova, 2014: 456) define como una transposición dentro de las narrativas de segundo grado. No resulta difícil, por otro lado, establecer una relación entre esta estructura tripartita en las tramas de Woolf, Brown y Vaughan/Dalloway y los actos de escribir, leer y vivir, siendo la literatura en sí misma motor de la novela (Cepedello, 2011: 5).

Las horas, al contrario que La señora Dalloway, se estructura en 22 capítulos alternos de cada una de las vidas de las protagonistas, perdiéndose el fluir constante de un tiempo atemporal tan propio de Woolf y de su novela. Los personajes de Las horas, en sus dos tramas ficcionales (las correspondientes a Laura Brown y Clarissa Vaughan), son un trasunto, variación o actualización libre de los personajes y de las relaciones de La señora Dalloway. En la revisión de Dalloway en el s. Xx que dibuja Cunningham, Vaughan puede mantener el romance ideado por Woolf entre Clarissa Dalloway y Sally Seton que, en los años veinte, estas no pudieron continuar. Junto con la habitación propia, es una de las libertades conquistadas por las mujeres en el s. xx. Sin embargo, como hiciera Richard Dalloway, Sally le regala flores a Vaughan: el problema de la incomunicación, también evidenciado en la trama de Laura Brown, sigue vigente en nuestros días.

El poeta Richard, amigo y examante al que Clarissa abandonó décadas atrás, es un trasunto del soldado Septimus de la novela de Woolf. Como señala Cepedello (2011: 4), Richard había escrito una novela, The Goodness of Time, cuyas protagonistas son la propia Clarissa y la madre del poeta, configurando un juego metanarrativo significativo en Las horas. El tortuoso proceso creativo de Richard recuerda a la ardua elaboración narrativa de la escritora inglesa. Clarissa, a lo largo del día, rememora la mańana de ese verano en que fueron amantes como la más feliz de su vida: «Richard era la persona que más amaba en el momento más optimista de su vida. Había parecido que era el principio de la felicidad, y a Clarissa la conmocionaba todavía» (Cunningham, 2003: 95). Richard tiene sida, lo cual le quita, quizás, sentido a sus horas, y vive recordando sus tiempos felices con su expareja Louis (nombre, porcierto, de uno de los personajes de Las olas). Louis es, a su vez, una versión del expretendiente de Clarissa Dalloway, Peter Walsh. 
Igualmente, y en cuanto a la temática, Las horas tiene conexiones directas y específicas con la novela original de La señora Dalloway. Cunningham, como Woolf, centra su novela en la muerte, en la locura y en el paso de las horas. En la frustración y la incomunicación. Se han desvanecido, sin embargo, el trasfondo político, la importancia de la guerra y la visión de la ciudad como un hormiguero de ingente e incontrolable vaivén. Los nuevos tiempos conllevan nuevas inquietudes: la homosexualidad, un nuevo feminismo o la aparición de las teorías queer.

Tal y como hemos apuntado, la celebración de la vida, uno de los temas fundamentales de La señora Dalloway (en contraposición con la evasión que supone el suicidio y la muerte), está muy presente en Cunningham. Pero el escritor norteamericano dispone diferentes desenlaces para cada una de las mujeres: el cumpleaños que prepara Laura no es suficiente para que resuelva sus horas, y la fiesta de Vaughan para Richard se convierte en un funeral. Cunningham, con la huida de Laura, ha añadido una opción, una alternativa, a las dos planteadas por Woolf (quizás las dos únicas posibles para una mujer en la época que le tocó vivir). Ante la muerte y la frivolidad Cunningham propone la evasión.

Centrándonos en las estrategias narrativas, el autor norteamericano se sirve de recursos narrativos woolfianos, presentes tanto en La señora Dalloway como en otras novelas. Se puede observar como en Las horas Cunningham recurre a un narrador omnisciente, que se traslada de un personaje a otro: un narrador de focalización interna, múltiple y variable. Al contrario que Woolf, el escritor norteamericano deja marcas de los cambios de narración entre personajes de forma más abundante. Si en La señora Dalloway el tránsito de un personaje a otro se concebía en una misma línea, sin «huellas» claras que nos indiquen estos cambios, en Las horas suelen ocurrir tras terminar un capítulo o un párrafo (Requena, 2007). Por ello, pese a asemejarse a la novela de Virginia Woolf, en cuanto a estrategias narrativas, Las horas es menos fluida y el narrador parece estar menos oculto. No asistimos, como en $\mathrm{La}$ señora Dalloway, a una expresión verbal del fluir de la consciencia, fragmentario en cada párrafo e incluso frase, brusco y confuso. $Y$ de la misma manera que en la novela de Virginia, conocemos los pensamientos de los personajes por medio de monólogos interiores, de una forma menos impresionista y coral que en La señora Dalloway.

Por otro lado, y como ya hemos referido, las evocaciones, sin bien con menos profundidad y hondura que en Woolf, son constantes en Las horas. Los objetos, las acciones, las escenas tienen una carga simbólica y rememoran un pasado añorado, como se desprende de este fragmento (Cunningham, 2003):

El viento mece las hojas, mostrando el verdor más brillante y grisáceo de su cara interna, y Clarissa siente el súbito deseo, con sorprendente urgencia, de que Richard esté aquí a su lado, ahora mismo; no el Richard que ha llegado a ser, sino el Richard de hace diez años; Richard el charlatán y sin miedo (24).

La dialéctica de Las horas con La señora Dalloway va más allá de la adopción de ciertas formas narrativas propias de Virginia Woolf. Cunningham inserta citas exactas de fragmentos enteros de La señora Dalloway y pinceladas más sutiles, referencias más indirectas, tanto de la novela como de la propia vida de Woolf. En 
los episodios de Woolf en 1923, Virginia repite frases de Clarissa Dalloway al mencionar Londres - «Qué juerga! ¡qué zambullida!»- y se reitera el tronar incesante del Big Ben de La señora Dalloway (Cunningham, 2003: 161). También Richard, cuando describe la mañana de junio (Cunningham, 2003: 192), parafrasea a Clarissa Dalloway al principio de la novela de Virginia: «Fresca como si fueran a repartirla a unos niños en la playa». La inclusión en los capítulos protagonizados por Laura de textos originales, citas, de La Señora Dalloway enfatiza la presencia de Virginia Woolf no solo como un personaje más.

Así, el uso de repeticiones de vocabulario en una misma frase de Woolf, Cunningham lo transforma en la repetición de palabras en distintos capítulos e incluso como recurso para la cohesión entre capítulos distintos, como podemos apreciar en el final de un capítulo de Woolf y el inicio de otro dedicado a Brown (Cunningham, 2003: 38-39). Así mismo, la ya indicada utilización magistral de Woolf de figuras retóricas (como la anadiplosis), que proporcionan cohesión al texto woolfiano, no se encuentran en abundancia en la novela de Cunningham. La fluidez del texto, que trata de conectar monólogos interiores, se ve mermada si la comparamos con La señora Dalloway.

En Cunningham hallamos una sintaxis menos arriesgada, más conservadora. Mientras Woolf desplaza el verbo lejos del sujeto o al final de la frase, creando impulso y suspense, el escritor mantiene un orden de los elementos de las frases bastante convencional (Pillière, 2004: 137). Sus monólogos interiores parecen mucho más organizados y diáfanos que los que leemos en La señora Dalloway, el caos y la falta de articulación del fluir de los pensamientos tan espontáneos en Woolf pierden esta naturalidad en Cunningham.

En otro orden de ideas, como escribe Requena (2007) y siguiendo a Genette, Las horas, pese a ser un relato singulativo, se sirve de la reiteración de acciones para caracterizar a sus personajes. Acciones frecuentes de las tres mujeres que se convierten en leitmotivs y que las unen narrativamente: colocar flores en un florero, fumar constantemente, mirarse al espejo o los besos que se dan entre personajes. De igual manera, objetos como las flores, la comida, las ventanas o los espejos cumplen esta función cohesionadora y simbólica.

Las flores son un leitmotiv constante en las páginas, tanto de La señora Dalloway como de Las horas. La primera frase de los primeros capítulos de las tres mujeres alude a las flores: las que Woolf hace comprar a Clarissa, las que aparecen en las primeras líneas que lee Brown y el pensamiento en voz alta de Clarissa Vaughan de ir a comprar las flores ella misma.

Los besos también unen las tres historias: el beso de Virginia a su hermana cuando la sirvienta Nelly se aleja, el beso de Laura a Kitty y los dos besos de Clarissa y Richard: el que Clarissa recuerda la mañana de verano de su romance y el de despedida, cuando Vaughan vuelve a los preparativos de la fiesta (Corrizzato y Goracci, 2014: 5).

En Las horas hallamos otros referentes evidentemente woolfianos: el agua y las olas, con el ya mencionado carácter simbólico en la novela de Cunningham: la alusión a la muerte de la escritora en el río sumergiéndose bajo sus olas. Así encontramos el agua que ofrece Vaughan a Louis cuando la visita justo antes de derrum- 
barse ante él, el agua del estanque cercano cuando se besaron Richard y Clarissa o el agua que brota de los parques de pino en Nueva York recordados por la misma Vaughan (Cunningham, 2003: 66, 89 y 123).

Cunningham inserta en su novela otros leitmotivs ausentes o más diluidos en La señora Dalloway. La cocina, espacio asignado tradicionalmente a la mujer, es el escenario en el que se desarrollan gran parte de los momentos dramáticos de Las horas: Laura Brown haciendo su tarta y recibiendo la visita de Kitty o Vaughan preparando la cena y desmoronándose ante Louis. También la comida es un elemento simbólico en Cunningham, como metáfora de la vida. Los alimentos son rechazados por los dos personajes suicidas de la novela, Virginia y Richard, la tarta de Laura es un fracaso y Clarissa observa el banquete de su fallida fiesta en su cocina.

En cuanto al tiempo, y dejando de lado el prólogo del suicidio, las tres tramas evocan el pasado sin dejar de avanzar en una continuidad más lineal que en la novela de Woolf. Si bien Cunningham evoca el pasado, sus retornos son menos abundantes, más concisos y, también, menos fragmentarios. La prosa mucho más experimental de Woolf, tratando de plasmar el fluir de la consciencia, difiere de unos recuerdos más cercanos al monólogo interior en Cunningham. En la narrativa woolfiana se difuminan los límites entre pasado y presente, ensoñación y recuerdo, consciencia e inconsciencia, recreando una suspensión temporal que hallamos mucho menos lograda en Las horas.

La obra de Cunningham, a modo de resumen, es un homenaje a Virginia Woolf con tintes autobiográficos. Las referencias a la escritora no solo se limitan a recrear parte de su vida y La señora Dalloway, como una variante de esta, sino que, más profundamente, hacen alusión a otras obras, a datos biográficos de Woolf y a teorías literarias como la importancia del lector en la narrativa. Cunningham, además, emplea los monólogos interiores y la dilatación del tiempo en una mañana de verano, para plasmar unos pensamientos dedicados al paso del tiempo y a la muerte. Pero se distancia de Woolf en no materializar el fluir de consciencia, en una sintaxis menos experimental, en una menor fragmentación y dispersión y en unas imágenes menos poéticas. La lectura en conjunto de la novela de Cunningham carece de la cohesión que encontramos en La señora Dalloway. En pocas palabras, Las horas es una novela más convencional que la escrita por Woolf en 1925.

\section{STEPHEN DALDRY Y LA SEÑORA DALLOWAY}

No se puede encontrar la paz evitando la vida.

Virginia Woolf a Leonard (Daldry, 2002)

Pero ¿tengo que enfrentarme a las horas verdad? A las horas después de la fiesta y a las horas después de esas. Richard a Clarissa (Daldry, 2002)

Antes incluso de que Cunningham terminara de escribir Las horas el productor Scott Rudin se había hecho con los derechos de la novela para llevarla a la gran pantalla. Rudin encargó la cinta al director británico Stephen Daldry (1960). 
Daldry apenas había rodado una película hasta ese momento, Billy Elliot, pero esta le había valido un gran éxito comercial y tres nominaciones a los premios Óscars. Daldry venía del mundo del teatro, con una amplia e importante labor como director artístico de la Royal Court Theatre. Para esta misma institución escribía guiones David Hare, quien sería el responsable del guion de Las horas.

El resultado del guion realizado por Hare, en términos de «fidelidad» es bastante respetuoso con la novela de Cunningham: mantiene la estructura tripartita y la linealidad temporal, los personajes y las temáticas planteadas en Las horas. El único cambio en la estructura que apreciamos es el añadido al final del film, ausente en el texto de Cunningham, del suicidio de Woolf, confiriendo a la película una estructura circular y conclusiva, en la que se nos sitúa al inicio del relato, remarcando la atemporalidad del film (Cepedello, 2011: 11). Los grandes desafíos para Hare fueron emular los mecanismos gracias a los cuales encajaban las historias en un todo y la plasmación en la cinta de los monólogos interiores, sin recurrir a analepsis o a la voz over, excepto en momentos puntuales. A la hora de resolver estos retos Hare comenta las soluciones que empleó (citado por Salazar, 2006):

Tuve que crear un cierto número de situaciones que expresaran lo que estaba pasando en el interior de la mente de los personajes. Por ejemplo, todo el tema del estado en el que el marido de Laura ha regresado de la guerra: necesitábamos saber cómo ha afectado al matrimonio la experiencia bélica. [...] lo tuve que explicitar en la escena de la fiesta de aniversario hacia el fin del film, donde él habla de la primera vez que la vio. Por supuesto, eso no se expresa abiertamente en libro (23).

Los diálogos en la película dan cuenta sutilmente de la vida interior de los personajes, vista por otros. Es el caso del personaje de Vanessa Bell, la hermana de la escritora, que gana peso en el filme cumpliendo la función de verbalizar pensamientos, explicando a sus hijos la personalidad de Virginia: en la escena en que encuentra al pájaro muerto en el jardín o en el salón de la casa de Woolf, momento en el que Virginia la besa. Hare pone en boca de Bell lo que en el texto de Cunningham expresa el narrador omnisciente. Las reflexiones, más abundantes en la prosa de Cunningham, sobre el verano en que Richard y Clarissa fueron amantes se sugieren en breves conversaciones entre ambos, desde las que el espectador imagina lo sucedido. El hastío de la vida rutinaria y vacía de Laura Brown, más detallada por medio de sus pensamientos, se advierte y sugiere en el film de forma más lacónica, con gestos y miradas. El guion de Hare, por tanto, elimina o transforma párrafos que en la narración de Cunningham revelan el pasado o los pensamientos de Brown y Dalloway y que explicarían sus emociones. Aunque se sacrifiquen estas aclaraciones en el filme, no son necesarias: comprendemos sus sentimientos a través de la actuación y la puesta en escena. Se han añadido escenas o diálogos, como los mencionados más arriba por Hare, que cumplen la función ilustrativa de estos fragmentos. Mención especial le debemos a la escena, no existente en la novela, del plano cenital de Brown tendida en la cama de hotel, inundada por las aguas. Se fusiona así, de forma magistral, el suicidio de la propia Woolf con el intento de Brown, añadiendo además una carga simbólica: Brown espera la muerte mientras acaricia su barriga de embarazada; la vida que está por llegar. 
Para la expresión de la interioridad de los personajes, sin recurrir a ensońaciones, flashback o la voz over (empleada solo en momentos puntuales como el inicio del filme o en la escena del hotel a la que acabamos de hacer referencia), Daldry se valió de las actuaciones de un excelente reparto. Para no distraer la atención de la expresividad de los actores evitó lo que él mismo denomina movimientos de cámara «decorativos». En Las horas la dirección, sobria y contenida, estuvo subordinada al trabajo de los actores y a las dinámicas de las puestas en escena. En palabras del propio director (citado por Salazar, 2006):

Dado que procedo del teatro se me hace difícil predeterminar mi visión de una escena [...] sin disponer previamente de una exploración de los actores. Para mí esta es la única manera de elaborar la dinámica y emoción de una escena. A partir de ahí puedo estudiar dónde y cómo poner la cámara (26-27).

Los continuos y exhaustivos ensayos previos al rodaje, en los que el reparto conocía el guion con absoluta precisión, contribuyeron decisivamente a la unión entre escenas, favoreciendo la sensación de cohesión general del texto fílmico. De nuevo recurrimos a las declaraciones de Daldry al respecto (citado por Salazar, 2006):

Una de las grandes satisfacciones de ensayar y de conocer el guion muy bien antes de rodarlo era que permitía saber cómo era el modelo de transición de una historia a otra. Con ritmo, lo que se contempla es, básicamente, lo ensayado, lo que es muy singular. Antes de rodar un solo metro, sabíamos con bastante precisión dónde una historia iba a dar paso a la otra, y cuál iba a ser el ritmo colectivo de todas ellas (27).

La película se inicia con la escena del prólogo, en la que un 28 de marzo de 1941, Woolf se suicida. En uno de los pocos momentos en que se recurre a un flashback de corto alcance, se alternan los planos en que ella va hacia el río con los que muestran cómo escribe una carta de despedida. Como en la novela de Cunningham, la figura de Virginia Woolf principia el relato y se nos revela como el cimiento del texto fílmico. La focalización es interna y múltiple, centrada en las tres mujeres y, muy puntualmente, en Richard. Desde la novela de Woolf, en la que abundaban los narradores, pasando por el texto de Cunningham, en el que se reducen significativamente, llegamos hasta Las horas de Daldry, en la que los personajes principales que centran la narración son las tres protagonistas.

Las claves para entender la dinámica y las estrategias narrativas se nos conceden desde los primeros minutos del metraje, que continuará siguiendo las pautas presentadas. El ruido de las olas llega al espectador antes que la imagen y, durante la escena de suicidio, Daldry nos muestra el cuerpo de Woolf bajo las aguas; referenciando uno de los elementos simbólicos woolfianos por excelencia: las olas, el río, lo acuático. Después del suicidio de la escritora, se nos introduce en las tres tramas: en Richmond, la primavera de 1923, el verano de 1951 en Los Ángeles, y un gélido invierno neoyorkino de 2002. Hare y Daldry insertan una variante respecto al texto de Cunningham para diferenciar visualmente las tres historias: mientras que en la novela las tres transcurren en verano, director y guionista enmarcan cada historia en diferentes estaciones. Los tonos verdes y azulados de la primavera de 1923 
dan paso a los amarillentos en las escenas de Brown (reforzados por las naranjas de la mesa, las flores amarillas o el traje marrón claro que viste al salir), hasta llegar a la Nueva York de Clarissa, gris, como los colores de la ropa que viste ella misma (Rincón, s.f: 71). Así, la luz y los colores difieren, pero sin perder la cohesión por la secuencialidad de las estaciones. Así lo describe Daldry (citado por Salazar, 2006):

Hay una oposición visual que funciona, de una historia a otra. Y mucho de ello consiste en cosas sencillas como el color. Hay una paleta distinta. Sin embargo, de algún modo, las respectivas paletas remiten directamente a las otras. Así que los elementos fusionadores se hallan en el patrón de montaje, en los movimientos de cámara y en las técnicas de procesados del film (25-26).

Junto con el abanico de colores y la luz, el vestuario unifica también visualmente las tres vidas de las protagonistas. En estrecha colaboración con el director de fotografía, Seamos McGarvey, la diseñadora de vestuario Ann Roth se basó en los atuendos del grupo de Bloomsbury para las vestimentas de las tres actrices principales. Como ella misma relata: «... sus colores [los del círculo de Bloomsbury] eran muy intensos, herrumbrosos, verdes y grises azulados. Quería vincular todo a esos colores. Julianne Moore viste los mismos colores que Meryl, que son los mismos que luce Kidman» (citada por Salazar, 2006: 26).

Como ya hemos referido, en los primeros minutos del metraje se establecen las pautas de las estrategias visuales y narrativas de Las horas. A diferencia de la novela de Cunningham, en la que el ritmo es pausado debido a los monólogos interiores, la rápida sucesión de escenas y secuencias de las tres tramas otorgan al relato fílmico una mayor agilidad, acercándose a la fluidez que caracteriza la novela de Virginia Woolf. El filme consigue trasmitirnos la simultaneidad que Cunningham no lograba, lastrado por la estructura en capítulos diferenciados. Recurriendo a Genette (1989: 143) y sus categorías temporales, Las horas emplea silepsis, que es «el hecho de juntar agrupaciones anacrónicas regidas por tal o cual parentesco, ya sea geográfico [...], temático o de otra índole».

El montaje del inicio, después del prólogo, alterna las tres historias en breves secuencias de cada una de ellas, en las que se realizan los mismos actos (analogías dinámicas): sus parejas llegan de la calle, ellas se levantan, se lavan la cara y realizan todas las acciones cotidianas habituales. El sonido sirve también para unificar la acción: escuchamos el reloj y las alarmas que consiguen despertarlas. Se narra así varias veces (tres por protagonista) lo que ocurre cada día de sus vidas. En una sucesión muy rápida de breves planos (que luego se ralentizará y cambiará el ritmo) ya se nos presenta a las tres mujeres, su carácter y su entorno. En relación con la novela, estas secuencias rápidas, casi pinceladas, acercan más la obra de Hare y Daldry a la de Virginia Woolf que a las pausas reflexivas y más inmóviles del texto literario de Cunningham. La combinación rápida de los planos de las tres mujeres consigue un efecto de simultaneidad y, como escribe Cepedello (2011: 10): «El tiempo en Las horas cinematográfica se abole».

Estas rápidas y tan bien cohesionadas transiciones siguen una pauta que será recurrente a lo largo del filme. Tras esta presentación de las tres protagonistas el montaje une temáticamente a las mujeres. Virginia coge su pluma, medita y piensa 
en voz alta: «Clarissa Dalloway decidió que compraría las flores ella misma», Laura Brown, en 1951, lee estas mismas palabras en la primera página de su ejemplar de La señora Dalloway y, tras una pausa, Clarisa Vaughan le anuncia a su pareja Sally que ella irá a comprar la flores. Con estas sencillas y breves secuencias Daldry y Hare nos dan la clave de unión temática de todo el filme: la novela de Woolf. Así mismo, nos colocan a la vez en la Inglaterra de 1920, en la década optimista de los años cincuenta en Los Ángeles y en la Nueva York postmoderna.

Las transiciones de la obra fluyen por medio de la utilización de los recursos fílmicos para lograr elementos de unión tanto temáticos como visuales. El encadenamiento de planos, superposición de sonidos, de las voces y de la música abolen las distinciones entre las tres épocas representadas. El modo en que se cohesionan los tres hilos narrativos, junto con el ritmo del montaje, refuerza la hipótesis de que la obra de Daldry se asemeja, en este sentido, más a la novela de Woolf que a la de Cunningham. Las repeticiones y contrastes visuales entre las tramas se multiplican en un brevísimo periodo de tiempo, como Woolf repetía palabras al comenzar y finalizar una frase (o al inicio de cada una de ellas) o como alternaba de narrador en una oración.

Las acciones que fusionan el relato fílmico disolviendo la separación entre planos y secuencias son innumerables: el resoplido de una Clarissa Vaughan sobrepasada da paso a un plano de Woolf expulsando humo de su cigarrillo, la puerta del baño que abre Laura precede a la puerta de la habitación que también franquea Leonard. Los planos en los que alguna de ellas yace o está sentada en la cama, no solo en el inicio del día, abundan. Una de las transiciones más significativas es en la que, tras un plano de Virginia Woolf tumbada en la tierra mirando un pájaro muerto vemos a Laura Brown en la cama: entendemos que está pensando, como Woolf, en la muerte.

A su vez, como elementos de cohesión, aparte de las acciones, están los objetos, que operan como leitmotivs de toda la película: las flores, tan recurrentes en La señora Dalloway y en Las horas de Cunningham, inundan el film. Las encontramos en los vestidos de Virginia y de Laura, en el delantal de Clarissa, en las sábanas, las cortinas y por todas partes en las tres casas, incluso en el marcapáginas que usa Laura para su volumen de La señora Dalloway.

Del mismo modo, encontramos la ventana, a través de la cual se observa el exterior y desde la que se arroja Richard. Las actitudes de las tres protagonistas en las ventanas definen determinantemente sus posiciones ante el mundo exterior: Virginia mira nerviosa y desconfiada a Leonard, Laura Brown sonriente y risueña despide a su marido tras el cristal (hasta que este se marcha y su gesto feliz se transfigura en un semblante triste) y Clarissa Vaughan (como la Dalloway de Woolf) observa entusiasmada el mundo exterior. Incluso Richard, al final del film, mira la ventana con tristeza justo antes de suicidarse.

Como en la novela de Cunningham, cobra especial relevancia la cocina, un espacio tan cotidiano en el que transcurren silenciosas tragedias y revelaciones: es el escenario en el que Clarissa se derrumba ante Louis recordando su amor por Richard y donde Kitty le descubre a Laura que teme tener un cáncer. Y de nuevo la comida, como símbolo de la vida, que continuamente se desecha; cuando Virginia 
se niega a comer, cuando Laura tira su tarta y cuando Vaughan también arroja, a diferencia de lo que ocurre en el texto del escritor norteamericano, los langostinos de su fiesta a la basura (Cánova, 2014: 465).

Así mismo, la presencia de lo acuático reaparece en Daldry. Las olas bajo las que se sumerge el cuerpo de Virginia en el río se convierten en las mismas olas, como ya hemos destacado, que anegan la cama de Brown en el hotel. Y Clarissa Vaughan, charlando con Louis en la cocina sobre Richard, no parece controlar el agua que sale de su grifo desbordando el fregadero justo cuando afloran sus miedos y resentimientos (Paúl, 2007: 107).

La música de Glass también dota de unidad a todo el metraje. El autor descartó componer la música diferenciando cada historia y cada época. Su pertenencia al movimiento minimalista propició que empleara la misma unidad musical, la misma base melódica con pequeñas variantes, para toda la película. A tenor de la cohesión que pretendía transmitir el relato fílmico de Las horas, nos parece sumamente acertada la elección de un compositor como Glass. La música de Las horas se construye con estructuras armónicas muy estáticas, que fluyen lentamente a través de las tres historias. Cada pie musical sirve también de puente entre los personajes y la utilización del piano ayuda a la sensación atemporal del film.

El sonido de la película fue también diseñado para recrear la atemporalidad: ruidos y voces que se solapan de una escena a otra, tanto entre secuencias distintas de la misma historia como en transiciones entre las diferentes épocas. Así mismo, en ocasiones tienen un efecto simbólico. Ejemplo de ello es el ruido de la sirena que se escucha justo antes de la escena del suicidio de Richard: premonición de la muerte cercana y, para los espectadores familiarizados con el texto de Woolf, una alusión a la sirena de la ambulancia (el triunfo de la civilización) que transportaba el cadáver de Septimus Warren Smith.

\section{CONCLUSIONES}

En el recorrido que hemos realizado a través de las tres obras se han analizado las estrategias narrativas, las semejanzas y diferencias entre los tres textos. La novela de Virginia Woolf, compleja y experimental, significó (junto con las obras de otros escritores modernistas) una ruptura con las formas de la novela tradicional. Los modos narrativos cinematográficos fueron una influencia incuestionable para los componentes del modernismo anglosajón. Pese a las críticas vertidas hacia el cine por Woolf, publicadas apenas un año después de la aparición de La señora Dalloway, la novelista había profetizado la capacidad del lenguaje cinematográfico para mostrar de forma más eficaz la simultaneidad temporal, tan propia de su narrativa. La agilidad de la prosa de La señora Dalloway, la continuidad ininterrumpida entre pasado y presente, los saltos incesantes entre narradores y la indeterminación entre consciencia e inconsciencia eran rasgos de una experimentación literaria que buscaba una expresión adecuada mediante el lenguaje de una nueva era, en la que el tiempo y la consciencia eran los temas fundamentales. Los pensamientos, mediante monólogos interiores y el fluir de la consciencia, tejen una narración impresionista 
y, como decimos, no regida por una línea temporal clara. Woolf captó de forma brillante el caos y la vorágine de imágenes, pasadas y presentes, que fluyen constantemente en la mente humana confundiendo recuerdos y pensamientos.

Michael Cunningham, en su libro homenaje Las horas, trata de adoptar algunas de las formas narrativas woolfianas, como el monólogo interior y la simultaneidad. Después de examinar sus estrategias narrativas, podemos asegurar que su obra carece de la agilidad ya mencionada de La señora Dalloway. Como hemos podido observar, la estructura tripartita del libro de Cunningham entorpece la sensación de suspensión temporal de la obra de Woolf. Además, cada una de las transiciones entre narradores es mucho menos sutil, más marcada y evidente, la sintaxis y la manipulación de los tiempos verbales son mucho más conservadoras y los monólogos interiores no se asemejan al fluir de la consciencia woolfiano, inarticulado y fragmentario. Si bien la intención de Cunningham no parece ser emular fielmente los mecanismos narrativos de Virginia -ni nosotros exigimos que así sea-, Las horas se configura como un tributo a Woolf y una actualización de los personajes y temas planteados en La señora Dalloway. La reconstrucción de la vida de la novelista y las tramas de las otras tres mujeres retoman de Woolf la preocupación por la incomunicación, la soledad, la enfermedad y la muerte, pero más centrado en cuestiones específicas como el sida y las nuevas corrientes feministas. La hondura de las temáticas de Virginia se desvanece en Las horas, siendo esta última una obra menos profunda a la vez que, como hemos ya referido, menos innovadora, creativa e imaginativa que La señora Dalloway.

En el texto fílmico hemos observado como la traslación al cine de los monólogos interiores y el fluir de la consciencia ha recurrido a distintas estrategias para su plasmación: los diálogos (que verbalizan pensamientos descritos en las novelas), el montaje, la puesta en escena y las actuaciones han servido para mostrar los sentimientos y pensamientos de los personajes. Las horas de Daldry y Hare, aunque retome la estructura de la novela de Cunningham, sí consigue mostrar la suspensión temporal de la novela de Woolf, gracias a los elementos del lenguaje cinematográfico que hemos descrito. Las transiciones, el guion, las actuaciones, la fotografía, la música y la dirección artística logran dotar de unidad al conjunto del relato cinematográfico a la vez que disuelven el estancamiento temporal presente en la novela del escritor norteamericano. Las tres historias se funden en una y el tiempo parece ser el mismo para todas ellas. Los modos narrativos de Woolf se asemejan más a las formas narrativas y recursos que operan en el film y la temática de La señora Dalloway está más presente en Las horas cinematográfica. El cine, como escribía Virginia Woolf, ha conseguido - a diferencia de la novela de Michael Cunninghamcaptar «los contrastes más fantásticos [...] con una velocidad tras la cual el escritor sólo podrá desvivirse en vano». 


\section{BIBLIOGRAFÍA}

Cánova, M. (2016): «The hours, de Stephen Daldry: tramas y tiempo narrativo», UNED Revista Signa, pp. 455-470.

Cepedello, M. (2011): «La doble construcción discursiva de Virginia Woolf: un estudio comparatista a propósito de Las Horas», Coloquio Internacional Montevideana VII. Voyaging in, voyaging out: Virginia Woolfy América Latina. Reflexiones desde Montevideo, Montevideo.

Chatman, S. (1990): Historia y discurso. La estructura de la narrativa en la novela y en el cine, Madrid, Taurus Humanidades.

Corrizzato, S. y Goracci, G. (2014): «Adjusting emotions/linguistic adaptation: cinematic multi-perspectives on The Hours», European Scientific Journal, pp. 265-272. Disponible en https://eujournal.org/index.php/esj/article/view/2898 [consultado: 2 de septiembre de 2018].

Cunningham, M. (1998): Las horas, Barcelona, El Aleph Editores, 2003.

Foucault, M (1970): La arqueología del saber, Buenos Aires, Siglo XXI Editores.

Genette, G. (1989): Figuras III, Barcelona, Editorial Lumen.

Gutiérrez, A. (2000): «Virginia Woolf, el fluir de la conciencia», A Parte Rei. Disponible en http:// serbal.pntic.mec.es/-cmunoz11/asuncion.pdf [consultado: 24 de agosto de 2018].

Marder, H. (1979): Feminismo y arte. Un estudio sobre Virginia Woolf, Madrid, Editorial Debate.

DAldry, S. (2002): Las horas. [Película], Estados Unidos, Paramount Pictures/Miramax.

Lázaro, A. (2005): El modernismo en la novela inglesa, Madrid, Editorial Síntesis.

López-Varela, A. (2002): Rescoldos de un tiempo: una exploración pluridisciplinar de la crisis de la representación del tiempo en ciencia y narrativa: (énfasis especial en Virginia Woolfy James Joyce), tesis doctoral, Universidad Complutense de Madrid. Disponible en https://biblioteca.ucm.es/tesis/fll/ucm-t26166.pdf [consultado: 3 de agosto de 2018].

Lozano, M. (2003): «La Virgen y el Lobo», en Woolf, La señora Dalloway, Madrid, Cátedra, pp. 9-145.

Pillière, L. (2004): «Michael Cunningham's The Hours: echoes of Virginia Woolf», Revue LISA/ LISA e-journal, vol. II, n. ${ }^{\circ}$ 5, pp. 132-143.

Requena, C. (2007): "Las Horas: de Virginia Woolf a Michael Cunningham y Stephen Daldry», Cyberhumanitatis, junio, n. ${ }^{\circ}$ 42. Disponible en https://web.uchile.cl/vignette/cyberhumanitatis/CDA/texto_simple2/0,1255,SCID\%253D21062\%2526ISID\%253D731,00.html [consultado: 19 de junio de 2018].

Rincón, M. (s.f.): «Las horas, una visión del mundo interior de Virginia Woolf-Mrs. Dalloway desde la novela de Michael Cunningham y la película de Stephen Daldry», Hojas universitarias, pp. 67-75.

Salazar, O. (2006): Las horas. El tiempo de las mujeres, Valencia, Tirant Lo Blanch.

Woolf, V. (1985): Moments of being, Londres, The Hogarth Press.

Woolf, V. (1931): Las olas, trad. Dámaso López, Madrid, Cátedra, 2003b.

Woolf, V. (1928): Orlando, trad. Jorge Luis Borges, Madrid, Alianza Editorial, 2004.

Woolf, V. (1926): «El cine», en Horas en una biblioteca, trad. Miguel Martinez-Lage, Barcelona, Seix Barral, 2016.

Woolf, V. (1925): La señora Dalloway, trad. Mariano Baselga, Madrid, Cátedra, 2003a.

Woolf, V. (1920-1924): The diary of Virginia Woolf. Volume 2. 1920-1924, Londres, Penguin Books, 1982. 